\section{Germination and Seedling Emergence of Primed Tomato and Asparagus Seeds under Adverse Conditions}

\author{
W.G. Pill ${ }^{1}$, J.J. Frett ${ }^{2}$, and D.C. Morneau ${ }^{3}$ \\ Delaware Agricultural Experiment Station, Department of Plant and Soil \\ Sciences, College of Agricultural Sciences, University of Delaware, \\ Newark, DE 19717-1303
}

\begin{abstract}
Additional index words. Asparagus officinalis, fluid drilling, Lycopersicon esculentum,
\end{abstract} osmotic stress, salinity, seed treatment, temperature stress

\begin{abstract}
Seeds of 'Ace 55' tomato (Lycopersicon esculentum Mill.) and 'Mary Washington' asparagus (Asparagus officinalis L.) were primed in $-0.8 \mathrm{MPa}(20 \mathrm{C}, 1$ week, dark) polyethylene glycol 8000 (PEG), synthetic seawater (INO), or $\mathrm{NaNO}_{3}$. Primed seeds of both species had a higher percentage of germination than untreated seeds only at $10 \mathrm{C}$ in nonsaline $(-0.05 \mathrm{MPa})$ medium, while in saline medium $(-0.6 \mathrm{MPa})$ priming increased the percentage of germination of tomato seeds at 10 and $30 \mathrm{C}$, and of primed asparagus seeds at 10 and 20C. Sodium nitrate was superior to PEG or INO for priming tomato seeds since it resulted in fewer days to $50 \%$ germination and higher final germination percentage in saline media at all temperatures. INO was a satisfactory alternative to PEG or $\mathrm{NaNO}_{3}$ for priming asparagus seeds since priming agent had little or no effect on germination. Seedling emergence from $\mathrm{NaNO}_{3}$-primed seeds of both species sown in a seedbed provided saline (- $0.39 \mathrm{MPa})$ irrigation was faster than from untreated dry-sown seeds. In the saline seedbed, priming increased final emergence percentage (FEP) from asparagus seeds, provided they were not subsequently dried, but had no effect on the percentage emergence of tomato seeds. Fluid-drilling primed or germinated seeds of either species enhanced seedling establishment in the saline seedbed by reducing time to $50 \%$ emergence and/or increasing FEP relative to primed, dried-b\&k or untreated seeds.
\end{abstract}

Priming involves exposing seeds to an external water potential low enough to restrict germination and yet permit pregerminative physiological and biochemical activities (Bradford, 1986). Commonly used priming agents include inorganic salts such as $\mathrm{CaCl}_{2}$, $\mathrm{KNO}_{3}, \mathrm{~K}_{2} \mathrm{HPO}_{4}$, or $\mathrm{Na}_{2} \mathrm{SO}_{4}$ and organic agents such as polyethylene glycol (PEG), mannitol, or sorbitol. As a priming agent, $\mathrm{NaNO}_{3}$ was superior to PEG for tomato seeds while synthetic seawater was as effective as PEG for asparagus seeds (Frett et al., 1991). Primed seeds have improved vigor, particularly under adverse seedbed conditions such as low temperature (Pill and Finch-Savage, 1988; Szafirowska et al., 1981), matric stress (Frett and Pill, 1989), or salinity (Wiebe and Muhyaddin, 1987).

Seed treatments following priming, however, can affect subsequent germination responses. If primed seeds are transferred

Received for publication 3 Aug. 1990. Published as Miscellaneous Paper 1333 of the Delaware Agricultural Experiment Station. Mention of trade names in this publication does not imply endorsement by the Delaware Agricultural Experiment Station of the products named, nor criticism of similar ones not mentioned. Contribution 272 of the Plant and Soil Sciences Dept. The cost of publishing this paper was defrayed in part by the payment of page charges. Under postal regulations, this paper therefore must be hereby marked $\boldsymbol{a d}$ vertisement solely to indicate this fact.

Associate Professor.

${ }^{2}$ Assistant Professor.

Undergraduate Student rier gel that then is delivered to the se before planting (Evans and Pill, 1988 1986). Such seeds have been considered
1984). Primed seeds of-asparagus (Evans and Pill, 1989), carrot, celery, and onion (Brocklehurst and Dearman, 1983) that had been dried before sowing germinated more slowly with at least some of the delay attributed to the increased time needed for seed re-imbibition.

The first experiment reported here was undertaken to determine the germination responses of tomato and asparagus seeds primed in PEG, synthetic seawater, or $\mathrm{NaNO}_{3}$ when subjected to osmotic and temperature stresses. The purpose of our second study was to determine seedling emergence response in a saline seedbed from primed seeds subjected to varying levels of drying before planting.

Priming agents and germination conditions. Seeds of 'Ace 55' tomato and 'Mary Washington' asparagus were primed in -0.8 MPa polyethylene glycol 8000 (PEG), Instant Ocean (INO, synthetic seawater, Aquarium Systems, Mentor, Ohio), or $\mathrm{NaNO}_{3}$ using methods described by Frett et al. (1991). The primed seeds were rinsed and transferred to $125 \times 80 \times 20$-mm transparent polystyrene boxes containing germination paper moistened with $15 \mathrm{ml}$ of nonsaline $(-0.05 \mathrm{MPa})$ or saline $(-0.6 \mathrm{MPa})$ solution for germination in the dark at 10,20 , or $30 \mathrm{C}$ (Table 1). The 4 (three priming agents and untreated seeds) $\times 2$ (salinity levels) $\times 3$ (temperatures) factorial was replicated five times ( 50 seeds per box) and arranged in completely randomized design. Germinated seeds (radicles visible) were counted and discarded each day. From the total number of seeds germinated, days to $50 \%$ germination $\left(\mathrm{G}_{50}\right)$ and final germination percentage (FGP) were calculated.

The FGP and $\mathrm{G}_{50}$ of tomato and asparagus seeds were influenced by the interaction of seed treatment with temperature and salinity during germination (Table 2). The greatest increase in FGP as a result of priming tomato ther gel that then is delivered to the seedbed, the "fluid drilling" planting technique (Gray,

directly from the priming solution to the germination medium, germination is more rapid "pregerminated" (Bradford, 1986) and can

Table 1. Seed and seedbed treatments for experiments with tomato and asparagus seed.

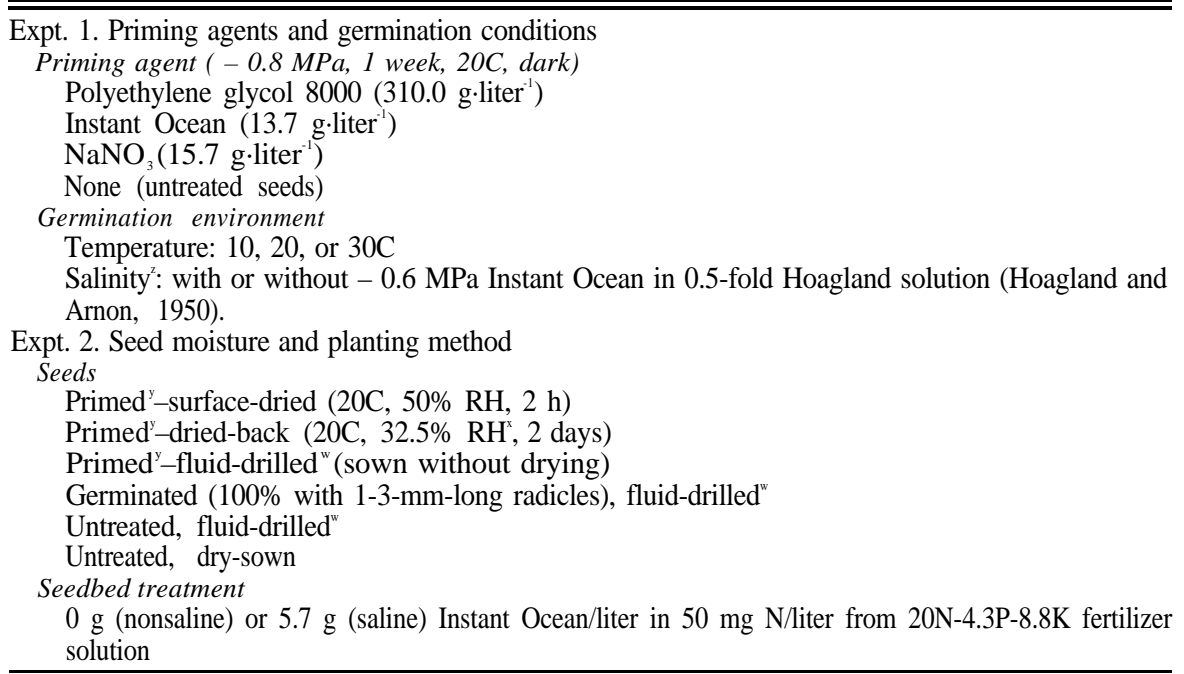

$25.6 \%, 24.7 \%$, or $23.8 \%(\mathrm{v} / \mathrm{v})$ of full-strength Instant Ocean $\left(38 \mathrm{~g} \cdot \mathrm{liter}^{-1}\right)$ at 10,20 , or 30C, respectively.

Primed in - $0.8 \mathrm{MPa} \mathrm{NaNO}_{3}, 1$ week, 20C, dark.

Stored over saturated $\mathrm{CaCl}_{2}$ (Winston and Bates, 1960).

"Seeds mixed in $1.5 \%$ (w/v) hydroxyethyl cellulose (N-gel). 
Table 2. Final germination percentage [FGP and angular transformation (in brackets)] and days to $50 \%$ germination $\left(\mathrm{G}_{50}\right)$ of tomato and asparagus seeds at 10,20 , or $30 \mathrm{C}$ in saline or nonsaline media as influenced by seed treatments.

\begin{tabular}{|c|c|c|c|c|c|c|}
\hline \multirow[b]{2}{*}{ Seed treatment ${ }^{2}$} & \multicolumn{2}{|c|}{$\begin{array}{l}\text { Germination } \\
\text { environment }\end{array}$} & \multicolumn{2}{|c|}{ Tomato } & \multicolumn{2}{|c|}{ Asparagus } \\
\hline & $\frac{\text { enviro }}{\text { Temp }\left({ }^{\circ} \mathrm{C}\right)}$ & $\frac{\text { sent }}{\text { Salinity }}$ & $\begin{array}{c}\text { FGP } \\
(\%)\end{array}$ & $\begin{array}{c}\mathrm{G}_{50} \\
\text { (days) }\end{array}$ & $\begin{array}{c}\text { FGP } \\
(\%)\end{array}$ & $\begin{array}{c}\mathrm{G}_{50} \\
\text { (days) }\end{array}$ \\
\hline PEG & $\begin{array}{l}20 \\
30\end{array}$ & $\begin{array}{l}- \\
+ \\
- \\
+ \\
- \\
+\end{array}$ & $\begin{array}{l}84[67] \\
18[24] \\
92[74] \\
88[70] \\
94[76] \\
70[57]\end{array}$ & $\begin{array}{r}13.6 \\
18.8 \\
1.1 \\
3.4 \\
1.0 \\
8.4\end{array}$ & $\begin{array}{ll}53 & {[47]} \\
19 & {[25]} \\
89 & {[71]} \\
82 & {[65]} \\
91 & {[73]} \\
90 & {[72]}\end{array}$ & $\begin{array}{r}9.0 \\
12.9 \\
2.4 \\
3.5 \\
1.2 \\
2.5\end{array}$ \\
\hline Instant Ocean & $\begin{array}{l}20 \\
30\end{array}$ & $\begin{array}{l}- \\
+ \\
- \\
+ \\
- \\
+\end{array}$ & $\begin{array}{l}68[56] \\
11[18] \\
93[74] \\
89[71] \\
91[73] \\
51[45]\end{array}$ & $\begin{array}{r}14.5 \\
17.6 \\
1.4 \\
3.5 \\
0.8 \\
6.6\end{array}$ & $\begin{array}{l}50[45] \\
21[27] \\
92[74] \\
84[67] \\
90[72] \\
90[72]\end{array}$ & $\begin{array}{l}9.4 \\
9.8 \\
2.2 \\
3.5 \\
1.0 \\
2.8\end{array}$ \\
\hline $\mathrm{NaNO}_{3}$ & $\begin{array}{l}10 \\
20 \\
30\end{array}$ & $\begin{array}{l}- \\
+ \\
- \\
+ \\
+ \\
+\end{array}$ & $\begin{array}{l}74[59] \\
22[27] \\
90[72] \\
92[76] \\
90[72] \\
72[58]\end{array}$ & $\begin{array}{l}0.8 \\
9.3 \\
0.7 \\
1.3 \\
0.5 \\
1.6\end{array}$ & $\begin{array}{l}56[48] \\
21[27] \\
91[73] \\
85[68] \\
93[77] \\
92[73]\end{array}$ & $\begin{array}{r}7.4 \\
12.3 \\
1.9 \\
3.1 \\
1.0 \\
2.6\end{array}$ \\
\hline Untreated & $\begin{array}{l}10 \\
20 \\
30\end{array}$ & $\begin{array}{l}- \\
+ \\
- \\
+ \\
- \\
+\end{array}$ & $\begin{array}{r}3[10] \\
2[8] \\
94[76] \\
78[63] \\
95[78] \\
48[44]\end{array}$ & $\begin{array}{r}16.3 \\
12.5 \\
2.8 \\
7.6 \\
2.2 \\
9.4\end{array}$ & $\begin{array}{r}6[14] \\
0[0] \\
90[72] \\
73[59] \\
91[74] \\
92[74]\end{array}$ & $\begin{array}{r}21.8 \\
--. \times \\
6.7 \\
10.4 \\
5.5 \\
7.9\end{array}$ \\
\hline $\mathrm{LSD}_{0.05}$ (three-way intera & ion) & & [8] & 3.1 & [6] & 2.3 \\
\hline $\begin{array}{l}\text { Significance } \\
\text { Seed treatment }(\mathrm{ST}) \\
\text { Salinity }(\mathrm{S}) \\
\text { Temperature }(\mathrm{T}) \\
\text { ST } \times \mathrm{S} \\
\mathrm{ST} \times \mathrm{T} \\
\mathrm{S} \times \mathrm{T} \\
\mathrm{ST} \times \mathrm{S} \times \mathrm{T}\end{array}$ & & & $\begin{array}{l}* * \\
* * \\
* * \\
* \\
* * \\
* * \\
* *\end{array}$ & $\begin{array}{l}* * \\
* * \\
* * \\
\text { NS } \\
* * \\
\text { NS } \\
* *\end{array}$ & $\begin{array}{l}* * \\
* * \\
* * \\
\text { NS } \\
* * \\
* * \\
* *\end{array}$ & $\begin{array}{l}* * \\
\text { NS } \\
* * \\
* * \\
* * \\
* * \\
* *\end{array}$ \\
\hline
\end{tabular}

${ }^{2}$ Seeds primed in $-0.8 \mathrm{MPa}$ PEG, Instant Ocean, or $\mathrm{NaNO}_{3}(1$ week, 20C, dark).

Without $(-)$ or with $(+)-0.6 \mathrm{MPa}$ Instant Ocean in 0.5-fold Hoagland solution.

${ }^{x}$ Regarded as missing since FGP $=0 \%$.

NS, ****Nonsignificant or significant at $P \leq 0.05$ or 0.01 , respectively.

Table 3. Days to $50 \%$ emergence $\left(\mathrm{E}_{50}\right)$, final emergence percentage [FEP, and angular transformation (in brackets)] and shoot dry weight (SDW) of tomato and asparagus seedlings as influenced by seed treatments and exposure to salinity.

\begin{tabular}{|c|c|c|c|c|c|c|c|}
\hline \multirow[b]{2}{*}{ Seed treatment ${ }^{z}$} & \multirow[b]{2}{*}{$\begin{array}{l}\text { Salinity } \\
\text { regime }^{\mathrm{y}}\end{array}$} & \multicolumn{3}{|c|}{ Tomato } & \multicolumn{3}{|c|}{ Asparagus } \\
\hline & & $\begin{array}{c}\mathrm{E}_{50} \\
\text { (days) }\end{array}$ & $\begin{array}{l}\text { FEP } \\
(\%)\end{array}$ & $\frac{\text { SDW }}{\text { (mg/plant) }}$ & $\begin{array}{c}\mathrm{E}_{50} \\
\text { (days) }\end{array}$ & $\begin{array}{l}\text { FEP } \\
(\%)\end{array}$ & $\begin{array}{c}\text { SDW } \\
\text { (mg/plant) }\end{array}$ \\
\hline $\begin{array}{l}\text { Primed-sd } \\
\text { Primed-db } \\
\text { Primed-fd } \\
\text { Germinated-fd } \\
\text { Untreated-fd } \\
\text { Untreated-ds }\end{array}$ & $\begin{array}{l}- \\
- \\
- \\
- \\
-\end{array}$ & $\begin{array}{l}2.8 \\
3.8 \\
1.8 \\
2.6 \\
6.1 \\
6.4\end{array}$ & $\begin{array}{l}88[70] \\
82[65] \\
92[74] \\
98[82] \\
93[74] \\
87[69]\end{array}$ & $\begin{array}{l}25.2 \\
21.2 \\
30.0 \\
28.5 \\
13.0 \\
13.4\end{array}$ & $\begin{array}{l}11.2 \\
14.3 \\
10.8 \\
11.7 \\
15.4 \\
15.7\end{array}$ & $\begin{array}{l}91[75] \\
86[68] \\
95[79] \\
86[69] \\
84[67] \\
79[63]\end{array}$ & $\begin{array}{l}45.9 \\
36.8 \\
43.0 \\
39.3 \\
42.7 \\
40.5\end{array}$ \\
\hline $\begin{array}{l}\text { Primed-sd } \\
\text { Primed-db } \\
\text { Primed-fd } \\
\text { Germinated-fd } \\
\text { Untreated-fd } \\
\text { Untreated-ds }\end{array}$ & $\begin{array}{l}+ \\
+ \\
+ \\
+ \\
+ \\
+\end{array}$ & $\begin{array}{r}5.0 \\
5.8 \\
1.8 \\
2.6 \\
10.7 \\
9.6\end{array}$ & $\begin{array}{l}81[65] \\
70[57] \\
84[66] \\
96[80] \\
61[51] \\
80[63]\end{array}$ & $\begin{array}{r}7.9 \\
6.9 \\
9.9 \\
11.3 \\
3.9 \\
4.1\end{array}$ & $\begin{array}{l}14.8 \\
16.7 \\
13.3 \\
11.7 \\
19.0 \\
18.7\end{array}$ & $\begin{array}{l}68[56] \\
33[34] \\
78[63] \\
85[73] \\
34[35] \\
41[40]\end{array}$ & $\begin{array}{l}21.8 \\
23.6 \\
24.5 \\
29.3 \\
22.0 \\
21.3\end{array}$ \\
\hline $\begin{array}{l}\mathrm{LSD}_{0.05} \\
\text { Significance }\end{array}$ & & 0.7 & [7] & 3.7 & 1.9 & [13] & 3.2 \\
\hline $\begin{array}{l}\text { Seed treatment (ST) } \\
\text { Salinity (S) }\end{array}$ & & $* *$ & ** & $* *$ & $* *$ & ** & $\begin{array}{c}\text { NS } \\
*\end{array}$ \\
\hline ST $\times S$ & & $* *$ & $* *$ & $* *$ & NS & $*$ & $*$ \\
\hline
\end{tabular}

Primed in $\mathrm{NaNO}_{3}(-0.8 \mathrm{MPa}, 20 \mathrm{C}, 1$ week, dark $)$; germinated $=100 \%$ germinated seeds; $\mathrm{sd}=$ surface-dried (20C, 50\% RH, $2 \mathrm{~h})$; db = dried-back (20C, 32.5\% RH, 2 days); fd = fluid-drilled; ds =dry-sown.

'Without (-) or with $(+)-0.6 \mathrm{MPa}$ Instant Ocean in $50 \mathrm{mg} \mathrm{N} /$ Iiter from $20 \mathrm{~N}-4.3 \mathrm{P}-8.8 \mathrm{~K}$

NS,***Nonsignificant or significant at $P \leq 0.05$ or 0.01 , respectively. and asparagus seeds occurred at $10 \mathrm{C}$ in both saline and nonsaline media. Seed priming is particularly beneficial at low temperatures (Pill and Finch-Savage, 1988; Szafirowska et al., 1981). The FGP of tomato or asparagus seeds in nonsaline media at $20 \mathrm{C}$ was not increased by priming, but in saline media at $20 \mathrm{C}$ the FGP of both species was increased by priming seeds in INO or $\mathrm{NaNO}_{3}$ (Table 2). At $30 \mathrm{C}$ in saline media, the FGP of tomato seeds primed in PEG or $\mathrm{NaNO}_{3}$ was higher than that of untreated seeds. Thus, salinity expanded the temperature range over which priming benefited tomato germination. The FGP of asparagus seeds at $30 \mathrm{C}$ in saline media was not increased by priming, revealing the greater salt tolerance of asparagus (Maas, 1986)

Since the $\mathrm{G}_{50}$ of tomato seeds primed in PEG or INO was lower than that of untreated seeds only at 20C in saline media (Table 2), the major effect of these two priming agents on tomato was that of increasing FGP. Sodium nitrate was superior to PEG or INO for priming tomato seeds since, relative to untreated seeds, $\mathrm{G}_{50}$ was decreased and FGP was increased under all conditions except 20 or $30 \mathrm{C}$ in nonsaline media. Faster germination from $\mathrm{KNO}_{3}$-primed than from PEGprimed tomato seeds was associated with a higher seed moisture content and presumably a more advanced stage of development (Alvarado and Bradford, 1988). Primed asparagus seeds had lower $G_{50}$ values than untreated seeds irrespective of germination environment and with priming agent exerting little or no effect (Table 2).

Seed moisture and planting method. Seeds of tomato and asparagus primed only in -0.8 $\mathrm{MPa} \mathrm{NaNO}$, were surface-dried (sd), driedback (db), or fluid-drilled (fd) (Table 1). In addition, untreated seeds or germinated seeds (radicles 1 to $3 \mathrm{~mm}$ long) were mixed in hydroxyethyl cellulose gel (N-gel, Aqualon Co., Wilmington, Del.) for fluid drilling. Fifty seeds were mixed in $15 \mathrm{ml}$ of the gel contained within a $125-\mathrm{ml}$ plastic bag so that extrusion through a cut corner would be 25 $\mathrm{ml} \cdot \mathrm{m}^{-1}$ of row. Seeds were sown dry or fluiddrilled at 50 seeds per $17 \times 12 \times 6$-cm plastic flat in five 1 -cm-deep $\times 12$-cm-long furrows. The growth medium was a commercial peat-lite (ProMix BX, Premier Brands, Stanford, Conn.). The flats were irrigated daily with $50 \mathrm{mg}$ N/liter from 20NA-3P-8.8K (Peters 20-10-20, W.R. Grace, Fogelsville, $\mathrm{Pa}$.). On alternate days, half of the flats received the fertilizer solution that contained $5.7 \mathrm{~g} \mathrm{INO/liter} \mathrm{to} \mathrm{provide} \mathrm{osmotic} \mathrm{stress}$ (Table 1)

The 2 (salinity) $\times 6$ (seed treatment) factorial was arranged in a randomized block design with four replications. The experiment was conducted under natural light (Oct.Nov. 1989) in a glasshouse with a day/night temperature range of 23 to $27 \mathrm{C} / 14$ to $17 \mathrm{C}$.

Days to $50 \%$ emergence $\left(\mathrm{E}_{50}\right)$ and final emergence percentage (FEP) were calculated from daily seedling emergence counts (epicotyl or hypocotyl first visible). Shoots of tomato and asparagus seedlings were cut at the growth medium surface 17 and 36 days 
after sowing, respectively, and the dry weight (mg/shoot) determined.

Tomato. FEP, $\mathrm{E}_{50}$, and shoot dry weights were influenced by the interaction of seed treatment and salinity (Table 3). Only germinated-fd seeds had a higher FEP than drysown, untreated seeds irrespective of salinity regime (Table 3). Primed-fd seeds had higher FEP than primed-db seeds regardless of salinity regime, suggesting that FEP was associated with the moisture content of primed seeds at the time of seed sowing.

Salinity increased the $E_{50}$ of seedlings from all treatments, except primed-sd seeds or germinated-fd seeds (Table 3). Slower seedling emergence from most seed treatments may reflect osmotically restricted water availability. The INO plus fertilizer solution yielded $-0.39 \mathrm{MPa}$ at 20C $\left(6.9 \mathrm{dS} \cdot \mathrm{m}^{-1}\right)$, while the fertilizer solution alone yielded $-0.04 \mathrm{MPa}$ at $20 \mathrm{C}\left(0.59 \mathrm{dS} \cdot \mathrm{m}^{-1}\right)$. Irrespective of salinity, primed-db seeds had higher $\mathrm{E}_{50}$ than primed-fd or primed-sd seeds, a response noted elsewhere (Evans and Pill, 1989; Frett and Pill, 1989; Pill, 1986) that, at least in part, may reflect the increased time required for re-imbibition. Seedling shoot dry weights generally were related inversely to $\mathrm{E}_{50}$ values (Table 3) as noted in asparagus (Evans and Pill, 1989) and parsley (Pill, 1986). Priming and pregermination increased shoot weight in nonsaline media regardless of seed drying treatment. In saline media, seedling shoot weights from primed$\mathrm{db}$ seeds were the same as those from untreated seeds, while other primed or pregerminated seeds resulted in higher shoot weights (Table 3).

Asparagus. The FEP and seedling shoot dry weights were influenced by the interaction of salinity and seed treatment, while $\mathrm{E}_{50}$ was influenced only by these main effects (Table 3). Salinity reduced FEP from all seed treatments except from germinated-fd seeds (Table 3). In nonsaline conditions, only primed-fd seeds had a higher FEP than untreated seeds, but in saline conditions, primedfd, primed-sd, and germinated-fd seeds had higher FEP than untreated seeds. Thus, sowing seeds of high moisture content, such as surface-drying primed seeds or fluid-drilling primed or germinated seeds, is an effective strategy to improve FEP in saline conditions. Francois (1987) noted that germination percentage of 'UC 157' asparagus seeds was not affected with up to $4.2 \mathrm{dS} \cdot \mathrm{m}^{-1}$ of conductance induced by salt (equal weights of $\mathrm{NaCl}$ and $\mathrm{CaCl}_{2}$ ), but above this threshold, germination was decreased by $1.5 \%$ with each unit increase in salinity up to $7.2 \mathrm{dS} \cdot \mathrm{m}^{-1}$. While the growth medium soluion would approach the $6.9 \mathrm{dS} \cdot \mathrm{m}^{-1}$ of the INO-fertilizer solution immediately after irrigation, values would increase between irrigations as water was lost by evapotranspiration. Thus, the low $(40 \%)$ FEP of untreated seeds in saline media (Table 3) would be expected.

Saline irrigation increased $\mathrm{E}_{50}$ of seeds from all treatments, except from germinated-fd seeds (Table 3). As with tomato seeds, the $\mathrm{E}_{50}$ of primed-db asparagus seeds was higher than from primed-fd or primed-sd seeds. Under saline conditions, germinated-fd seeds and primed-fd seeds gave $\mathrm{E}_{\mathrm{s} 0}$ values lower by 7.0 and 5.4 days, respectively, than the 18.7day $\mathrm{E}_{50}$ value of untreated seeds.

Salinity decreased shoot dry weights of asparagus (Table 3 ) by an average of $42 \%$, but of tomato by an average of $67 \%$, as would be expected given the greater salt tolerance of asparagus (Maas, 1986). Compared with the untreated seeds, only primed-sd seeds had heavier shoots in nonsaline media, and only germinated-fd seeds had higher shoot weights in saline media.

We have shown that $\mathrm{NaNO}_{3}$ was superior to PEG or INO for priming tomato seeds, but that priming agent had little or no effect on the germination of asparagus seeds. When exposed to saline irrigation, primed seeds of both species regardless of drying treatment had lower $\mathrm{E}_{50}$ values than dry-sown untreated seeds. In this stressful seedbed, priming did not increase FEP from tomato seeds but increased FEP from asparagus seeds, provided they were not dried-back. Fluiddrilling primed or germinated seeds enhanced the establishment of both species in a saline seedbed relative to dry-sowing primed-db or untreated seeds.

\section{Literature Cited}

Alvarado, A.D. and K.J. Bradford. 1988. Priming and storage of tomato (Lycopersicon esculentum) seeds. I. Effects of storage temperature on germination rate and viability. Seed Sci. \& Technol. 16:601-612.

Bradford, K.J. 1986. Manipulation of seed water relations via osmotic priming to improve germination under stress conditions. HortScience 21:1105-1112.

Brocklehurst, P.A. and J. Dearman. 1983. Interactions between seed priming treatments and nine seed lots of carrot, celery, and onion. I. Laboratory germination. Ann. Applied Biol. 102:577-584.

Evans, T.A. and W.G. Pill. 1989. Emergence and seedling growth from osmotically primed or pregerminated seeds of asparagus (Asparagus officinalis L.). J. Hort. Sci. 64:275-282.

Francois, L.E. 1987. Salinity effects on asparagus yield and vegetative growth. J. Amer. Soc. Hort. Sci. 112:432-436.

Frett, J.J. and W.G. Pill. 1989. Germination characteristics of osmotically primed and stored impatiens seeds. Scientia Hort. 40:171-179.

Frett, J.J., W.G. Pill, and D.C. Morneau. 1991. A comparison of priming agents for tomato and asparagus seeds. HortScience 26:1158-1159.

Gray, D. 1984. The role of fluid drilling in plant establishment. Aspects Applied Biol. 7:153-172.

Hoagland, D.R. and D.I. Arnon. 1950. The waterculture method for growing plants without soil. Calif. Agr. Expt. Sta. Circ. 347.

Maas, E.V. 1986. Salt tolerance of plants. Applied Agr. Res. 1:12-26.

Pill, W.G. 1986. Parsley emergence and seedling growth from raw, osmoconditioned, and pregerminated seeds. HortScience 21:1134-1136.

Pill, W.G. and W.E. Finch-Savage. 1988. Effects of combining priming and plant growth regulator treatments on the synchronization of carrot seed germination. Ann. Applied Biol. 113:383389 .

Szafirowska, A., A.A. Khan, and N.H. Peck. 1981. Osmoconditioning of carrot seeds to improve seedling establishment and yield in cold soil. Agron. J. 73:845-848.

Weibe, H.J. and T. Muhyaddin. 1987. Improvement of emergence by osmotic treatment in soil of high salinity. Acta Hort. 198:91-100.

Winston, P.W. and D.H. Bates. 1960. Saturated solutions for the control of humidity in biological research. Ecology 41:232-237. 